Научная статья

УДК 330.3

DOI 10.18101/2304-4446-2020-4-25-32

\title{
ПРОБЛЕМЫ КАЧЕСТВА ЖИЗНИ ТРУДЯЩЕЙСЯ МОЛОДЕЖИ РЕСПУБЛИКИ БАШКОРТОСТАН
}

\section{(C) Барлыбаев Адигам Агзамович}

доктор экономических наук, профессор,

Сибайский институт (филиал) Башкирского государственного университета

Россия, 453837, г. Сибай, ул. Белова, 21

старший научный сотрудник,

Сибайский филиал Института стратегических исследований

Республики Башкортостан

Россия, 453837, г. Сибай, ул. Кутузова, 1

adigam@mail.ru

\section{(c) Ишназарова Зульфия Мирзовна}

кандидат экономических наук, старший научный сотрудник, Сибайский филиал Института стратегических исследований Республики Башкортостан Россия, 453837, г. Сибай, ул. Кутузова, 1 zmsalikhova@mail.ru

\section{(C) Рахматуллин Ильдар Мажитович}

кандидат экономических наук, и. о. заведующего кафедрой уголовного и гражданского права и процесса,

Сибайский институт (филиал) Башкирского государственного университета Россия, 453837, г. Сибай, ул. Белова, 21

ildar_bgu@mail.ru

\section{(C) Ситнова Инна Алексеевна}

доктор экономических наук, профессор,

Сибайский институт (филиал) Башкирского государственного университета Россия, 453837, г. Сибай, ул. Белова, 21

старший научный сотрудник,

Сибайский филиал Института стратегических исследований

Республики Башкортостан

Россия, 453837, г. Сибай, ул. Кутузова, 1

sinn01@mail.ru

Благодарность: работа подготовлена за счет финансового обеспечения выполнения государственного задания «Устойчивое развитие Башкирского Зауралья как единой социо-эколого-экономической системы» ГАНУ «Институт стратегических исследований Республики Башкортостан» на 2020 год (руководитель — Я. Т. Суюндуков)

Аннотация. В статье рассматриваются проблемы трудящейся молодежи региона, основными из них являются уровень заработной платы и жилищного обеспечения, отсутствие единого подхода к возрастной градации трудящейся молодежи, разрозненность информационной платформы по мерам регулирования условий жизни. Приве- 
ден обзор мер поддержки молодежи в Российской Федерации и отдельно программ поддержки трудящейся молодежи в соседних регионах. Сделан вывод, что, несмотря на проводимую работу и реализуемые государственные программы по обеспечению уровня и качества жизни молодежи, в них отсутствуют меры и мероприятия, регулирующие уровень и качество жизни именно трудящейся молодежи в возрасте до 35 лет, возникает необходимость в определении их в отдельную категорию защищаемых лиц.

Ключевые слова: качество жизни; трудящаяся молодежь; программы поддержки; трудовые ресурсы; население.

\section{Для цитирования}

Барлыбаев А. А., Ишназарова 3. М., Рахматуллин И. М., Ситнова И. А. Проблемы качества жизни трудящейся молодежи Республики Башкортостан // Вестник Бурятского государственного университета. Экономика и менеджмент. 2020. № 4. С. 25-32.

Молодое поколение представляет собой стратегический ресурс развития экономики страны и региона. Трудящаяся молодежь, в числе трудящихся других возрастных категорий, вносит непосредственный вклад в экономическое развитие страны и региона [1-3].

В Российской Федерации проживает 146,7 млн человек ${ }^{1}$, в том числе 82,6 млн трудоспособного возраста, из них в возрасте 15-34 лет - 35,9 млн человек. Сокращение численности молодежи до 25 млн человек к 2025 г. отрицательно будет влиять на социально-экономическое развитие Российской Федерации ${ }^{2}$.

Поскольку рынок труда выступает одним из важнейших элементов экономической системы, Стратегия национальной безопасности Российской Федерации, утвержденная указом Президента РФ от 31 декабря 2015 г. № 683, закрепляет его как приоритетное направление ${ }^{3}$.

Рынок труда является важным критерием повышения качества жизни населения. В Стратегии национальной безопасности Российской Федерации наряду с другими факторами указывается необходимость организации благоприятных условий для улучшения социального статуса, качества труда и достойной оплаты [4-5]. Однако отдельные проблемы российского рынка труда отнесены к главным стратегическим угрозам национальной безопасности страны и касаются прогрессирующей трудонедостаточности. Низкий уровень рождаемости и снижение смертности повлекли за собой сокращение удельного веса лиц трудоспособного возраста - основы трудовых ресурсов страны. Если в 2002 г. их доля в общей численности населения составляла $62 \%$, то уже к 2015 г. сократилась до $58 \%$. Напротив, удельный вес лиц пожилого возраста возрос с 21 до 24\%, что свидетельствует о возрастающей пенсионной нагрузке на трудоспособное население.

\footnotetext{
${ }^{1}$ На 1 января 2020 г. по данным Росстата. Численность населения Российской Федерации по полу и возрасту на 1 января 2020 г. Федеральная служба государственной статистики [Электронный ресурс]. URL: https://rosstat.gov.ru/bgd/reg1/b20_111/Main.htm

${ }^{2}$ Стратегия развития молодежи Российской Федерации на период до 2025 г. [Электронный ресурc]. URL: http://static.government.ru/media/files/ceFXleNUqOU.pdf

${ }^{3}$ O Стратегии национальной безопасности Российской Федерации: указ Президента РФ от 31 декабря 2015 г. № 683 [Электронный ресурс]. URL: http://www.consultant.ru
} 
А. А. Барлыбаев, З. М. Ишназарова, И. М. Рахматуллин, И. А. Ситнова. Проблемы качества жизни трудящейся молодежи Республики Башкортостан

В Республике Башкортостан основными демографическими проблемами являются снижение рождаемости и старение населения, миграционный отток и сокращение доли населения в трудоспособном возрасте [6-7; 10].

К 2018 г. происходит резкое снижение численности постоянно проживающего населения в республике - с 4066,9 до 4063,2 тыс. чел. (на 3,7 тыс. чел.) по сравнению с 2017 г. ${ }^{1}$ При этом данное уменьшение произошло за счет сельского населения. Городское население увеличилось на 3,1 тыс. человек и в 2018 г. составило 2522,0 тыс., численность сельского населения уменьшилась на 6,7 тыс. и была равна 1541,2 тыс. При этом тенденция уменьшения численности постоянного населения в республике наблюдается еще с 2015 г. (рис. 1).

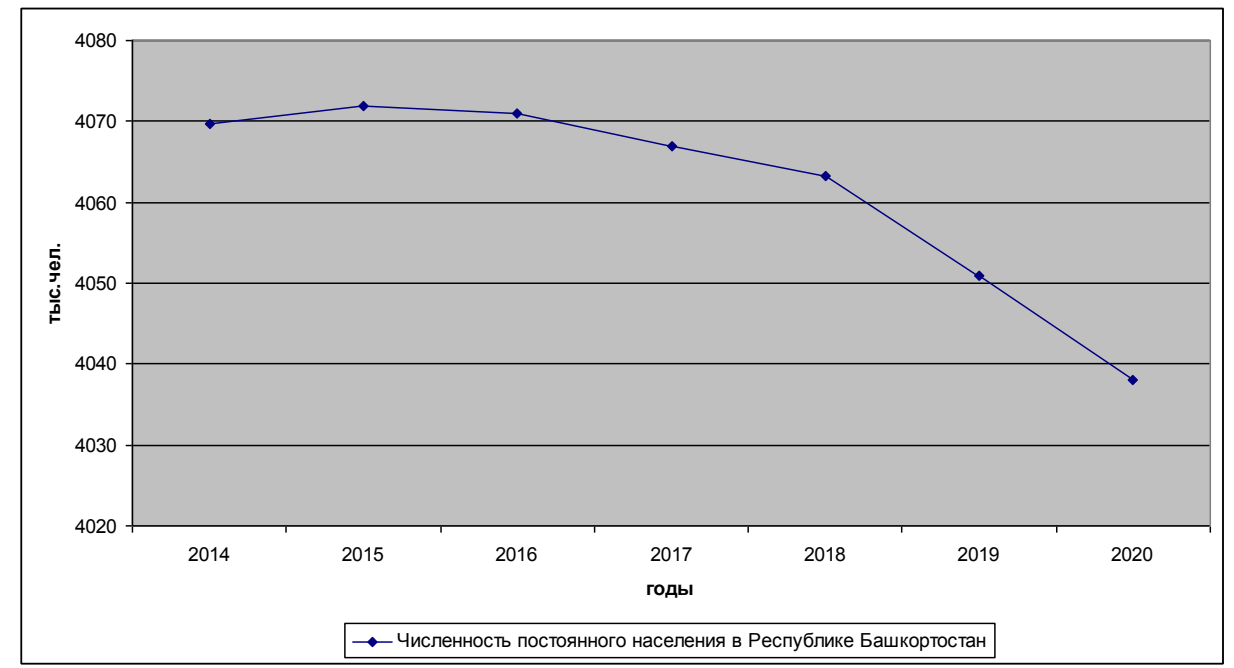

Рис. 1. Численность постоянного населения в Республике Башкортостан (на начало года)

В Республике Башкортостан доля лиц моложе трудоспособного возраста меньше доли населения старше трудоспособного возраста, и это превышение сохраняется несколько лет. Продолжилось уменьшение численности населения трудоспособного возраста. В целом по Российской Федерации за 2017 г. снижение составило 960,3 тыс. чел., в Республике Башкортостан - 33,1 тыс. чел. (из них $-19,7$ тыс. чел. - за счет смены поколений). В сельской местности население трудоспособного возраста снизилось на 14,5 тыс. чел., в городской местности - на 18,6 тыс. чел. ${ }^{2}$

Важную роль в экономическом развитии играют трудовые ресурсы, в особенности занятое население, поскольку именно они производят продукты, товары и услуги. Численность трудовых ресурсов в Республике Башкортостан имеет тенденцию к снижению, как и численность занятого населения (рис. 2).

\footnotetext{
${ }^{1}$ Население. Территориальный орган Федеральной службы государственной статистики по Республике Башкортостан [Электронный ресурc]. URL: https://bashstat.gks.ru/ folder/26906

${ }^{2}$ Там же.
} 


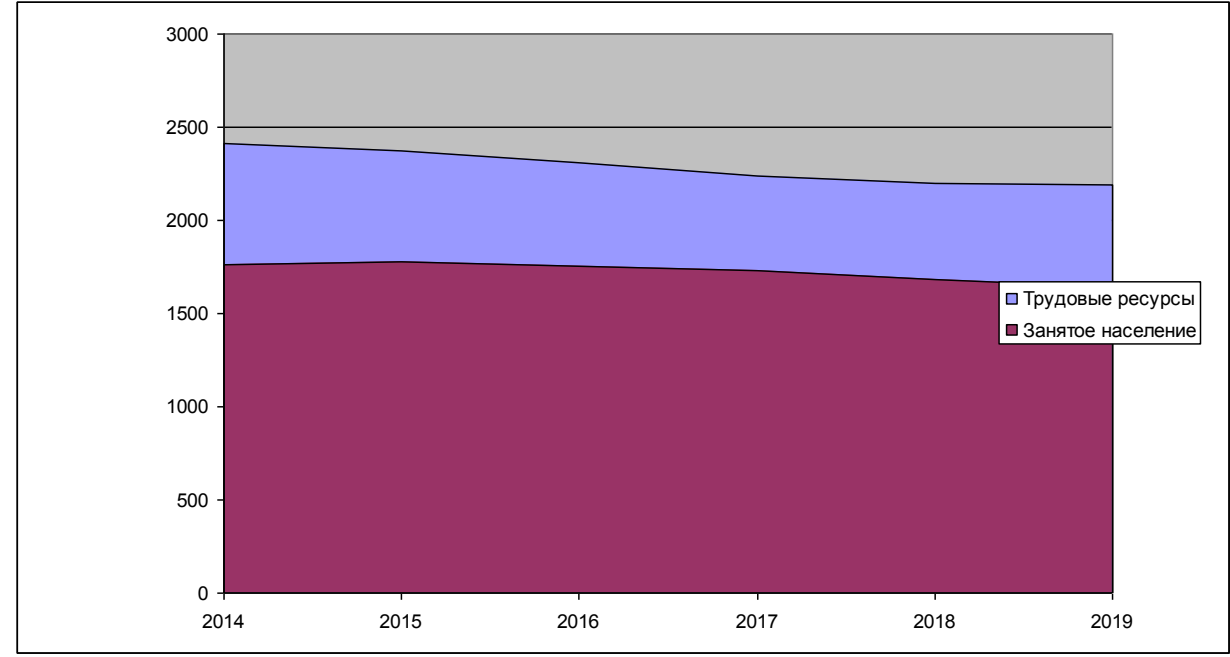

Рис. 2. Трудовые ресурсы и занятое население Республики Башкортостан

Молодежь 15-34 лет в возрастном составе республики составляет 26,5\% (табл. 1). Данные о занятых лицах в возрасте 15-34 лет в официальной статистике отсутствуют.

Таблица 1

Возрастной состав населения Республики Башкортостан на 1 января 2018 г.

(тыс. чел.)

\begin{tabular}{|l|c|c|c|}
\hline & Оба пола & Мужчины & Женщины \\
\hline Все население & 4063,3 & 1905,5 & 2157,8 \\
\hline $\begin{array}{l}\text { Население в возрасте } \\
15-34 \text { лет, в том числе: }\end{array}$ & 1079,5 & 544,7 & 534,8 \\
\hline $15-19$ & 204,1 & 102,3 & 101,8 \\
\hline $20-24$ & 217,0 & 107,2 & 109,8 \\
\hline $25-29$ & 312,6 & 159,9 & 152,6 \\
\hline $30-34$ & 345,7 & 175,2 & 170,5 \\
\hline
\end{tabular}

Повышение конкуренции между регионами, важность сохранения и преумножения промышленного, агропромышленного, образовательного, научного и других видов потенциалов республики усиливают роль трудовых ресурсов, а именно трудящейся молодежи как стратегического ресурса территории. В этих условиях особенно важно создать соответствующие условия жизни молодого поколения, стремиться как можно быстрее решить проблемы жилья, условий труда, адаптации на рабочем месте и, возможно, на новом месте жизни.

На рынке труда Республики Башкортостан существует четыре основные проблемы. Во-первых, резкое снижение численности населения. К 2018 г. происходит резкое снижение численности постоянно проживающего населения в рес- 
публике - с 4066,9 до 4063,2 тыс. чел. (на 3,7 тыс. чел.) по сравнению с 2017 г. ${ }^{1}$ При этом данное уменьшение произошло за счет сельского населения. Вовторых, доля лиц моложе трудоспособного возраста меньше доли населения старше трудоспособного возраста, и это превышение сохраняется несколько лет. В-третьих, сохраняется снижение численности населения трудоспособного возраста. В целом по России за 2017 г. снижение составило 960,3 тыс. чел., в Республике Башкортостан - 33,1 тыс. (из них -19,7 тыс. человек - за счет смены поколений). В-четвертых, численность трудовых ресурсов в Республике Башкортостан имеет тенденцию к снижению, как и численность занятого населения.

При существующих четырех основных проблемах рынка труда возникает острая необходимость усиления той категории населения, которая только начинает реально производить продукты и услуги и улучшать экономические показатели региона, - это молодые люди до 35 лет. Однако у этой категории людей существуют проблемы, которые ограничивают их трудоспособность и производительность труда. Это уровень и качество жизни. Улучшение условий жизни трудящейся молодежи значительно повышает их производительность, следовательно, и экономические показатели региона. Среди основных проблем трудящейся молодежи необходимо отметить: 1) уровень заработной платы и жилищного обеспечения, 2) отсутствие единого подхода к возрастной градации «трудящаяся молодежь» в РБ, 3) разрозненность информационной платформы по мерам регулирования условий жизни молодежи РБ и другие.

Правительством Российской Федерации в 2014 г. утвержден документ «Об утверждении основ государственной молодежной политики РФ на период до 2025 г.» ${ }^{2}$, согласно которому приоритетными задачами государственной молодежной политики являются:

- воспитание системы ценностей, учитывая многонациональную основу Российской Федерации;

- создание условий для самообразования молодежи, развитие инновационных образовательных и воспитательных технологий;

- развитие ценностей здорового образа жизни и формирование экологической культуры, повышение уровня культуры безопасности жизнедеятельности молодежи;

- обеспечение благоприятных условий для молодых семей, которые направлены на повышение рождаемости, формирование ценностей семейной культуры и образа успешной молодой семьи;

- формирование информационного поля и интенсификация механизмов обратной связи между государственными и общественными структурами, благоприятных для развития молодежи, также повышение эффективности использования информационной инфраструктуры в интересах патриотического и гражданского воспитания молодежи.

\footnotetext{
${ }^{1}$ Рынок труда и занятость населения. Территориальный орган Федеральной службы государственной статистики по Республике Башкортостан [Электронный pecypc]. URL: https://bashstat.gks.ru/folder/26906

${ }^{2}$ Об утверждении основ государственной молодежной политики РФ на период до 2025 г.: распоряжение Правительства РФ от 29 ноября 2014 г. № 2403-р [Электронный ресурс]. URL: http://docs.cntd.ru/document/420237592
} 
Анализ опыта управления качеством жизни трудящейся молодежи близлежащих соседей-регионов показал, что в некоторых создаются специальные программы для данной категории населения. Так, в Республике Татарстан существует программа «Работающая молодежь Республики Татарстан на 20192022 гг.», которая ориентирована на молодежь 14-30 лет. Среди имеющихся проблем отмечаются и проблемы материальной обеспеченности: обеспечение жильем молодых семей, трудоустройство молодежи, создание комфортного пространства для развития человеческого капитала, уровень правонарушений среди молодежи.

Существующие проблемы должны в определенной степени решить ряд принимаемых мер. Среди них основные: информационное обеспечение работающей молодежи о действующих механизмах социальной поддержки, формирование и развитие молодежных сообществ, вовлечение трудящейся молодежи в рационализаторскую и изобретательскую деятельность. Также вовлечение молодежи, занятой на предприятиях и в организациях, в молодежные проекты и программы региона и содействие профессиональному, патриотическому, интеллектуальному и творческому развитию работающей молодежи, повышению правовой грамотности .

В Свердловской области реализуется Концепция поддержки работающей молодежи на период до 2020 г., нацелена на население в возрасте 16-30 лет (потенциально «работающая молодежь»). Основной целью поддержки работающей молодежи Свердловской области является эффективная самореализация работающей молодежи, а также создание для этого соответствующих условий и возможностей, данные меры должны способствовать в том числе инновационному развитию региона ${ }^{2}$. Среди основных направлений для создания условий и возможностей реализации молодежи - обеспечение информационного пространства и формирование программ поддержки молодых семей и программ поддержки различных возрастных групп работающей молодежи, которые будут помогать им профессионально развиваться, также содействовать закреплению молодых трудовых ресурсов на селе ${ }^{3}$.

В Республике Башкортостан ведется большая работа, разработаны и реализуются государственные программы «Социальная защита населения Республики Башкортостан», «Регулирование рынка труда и содействие занятости населения в Республике Башкортостан», которые призваны поддерживать условия и качество жизни работающих лиц, молодых семей, молодых специалистов [8-9]. Однако отсутствует комплексный подход к обеспечению уровня и качества жизни трудящейся молодежи. Так, анализ действующих нормативно-правовых актов показал, что в них отсутствуют меры и мероприятия, регулирующие уровень и качество жизни именно трудящейся молодежи в возрасте до 35 лет, необходимо выделение их в отдельную категорию защищаемых лиц.

\footnotetext{
${ }^{1}$ Союз молодёжи предприятий и организаций Республики Татарстан [Электронный реcypc]. URL: https://smpo-rt.ru/program

2 O Концепции поддержки работающей молодежи Свердловской области на период до 2020 г. [Электронный ресурс]. URL: http://docs.cntd.ru/document/553234000

${ }^{3}$ Там же.
} 
Литература

1. Ишназаров Д. У. Взаимодействие трудовой миграции и рынка труда в Республике Башкортостан // Будущее сферы труда: глобальные вызовы и региональное развитие: сб. ст. междунар. форума; под ред. Г. Р. Баймурзиной, Р. М. Валиахметова. Уфа, 2019. C. $379-385$.

2. Ишназаров Д. У. Современные тенденции миграционных процессов на рынке труда // Устойчивое развитие территорий: теория и практика: материалы IX Bcepoc. науч.практ. конф. Уфа, 2018. С. 58-60.

3. Ишназарова 3. М., Ишназаров Д. У., Суюндуков Я. Т. Факторы, определяющие качество жизни человеческого капитала региона // Вестник Алтайской академии экономики и права. 2020. № 4-2. С. 200-207.

4. Ахметов В. Я., Бердникова Г. И. Самозанятость в социально-экономической структуре российского села // Устойчивое развитие территорий: теория и практика: материалы III Всерос. науч.-практ. конф. / под ред. Я. Т. Суюндукова, А. А. Барлыбаева, Ф. М. Сулейманова. Уфа, 2011. С. 27-29.

5. Бердникова Г. И. Роль субъектов малого предпринимательства и самозанятых в территориальном развитии // Устойчивое развитие территорий: теория и практика: материалы X Всерос. науч.-практ. конф. с междунар. участием: в 2 т. Уфа, 2019. С. 195-198.

6. Ишназаров Д. У., Ишназарова 3. М. Социо-эколого-экономическая оценка качества жизни сельского населения в районах Башкирского Зауралья (по результатам социологических исследований) // Единство. Гражданственность. Патриотизм: сб. науч. тр. к 100-летию Республики Башкортостан. Уфа, 2019. С. 114-118.

7. Мамлеева Э. Р., Акчулпанов Ю. К., Марьина А. В. Оценка эффективности использования трудовых ресурсов в Республике Башкортостан // Современная конкуренция: состояние, проблемы и тренды развития: сб. ст. междунар. науч.-практ. конф. Уфа, 2018. C. $118-120$

8. Мухаметова А. Д. Система управления социально-экономическим развитием региона на основе вклада человеческого капитала // Экономика и менеджмент систем управления. 2020. № 1(35). С. 36-42.

9. Трофимова Н. В., Лобанова В. А. Современное состояние качества жизни населения в регионах // Доклады Башкирского университета. 2016. Т. 1, № 3. С. 551-556.

10. Янтурина А. С., Бердникова Г. И. Эффективная занятость как фактор устойчивого развития социальной экологии региона // Вестник Оренбургского государственного университета. 2009. № 6(100). С. 526-528.

\section{ISSUES ON THE QUALITY OF LIVING OF WORKING YOUTH IN THE REPUBLIC OF BASHKORTOSTAN}

Adigam A. Barlybaev

Dr. Sci. (Econ.), Prof.,

Sibay Institute (branch) of Bashkir State University,

21 Belova St., Sibay, Russia

Senior Researcher,

Sibay Branch of Institute for Strategic Studies of the Republic of Bashkortostan,

1 Kutuzova St., Sibay, Russia

adigam@mail.ru

Zulfiya M. Ishnazarova

Cand. Sci. (Econ.), Senior Researcher,

Sibay Branch of Institute for Strategic Studies of the Republic of Bashkortostan

1 Kutuzova St., Sibay, Russia

zmsalikhova@mail.ru 
Ildar M. Rakhmatullin

Cand. Sci. (Econ.), Acting Head of Department of Criminal and Civil Law and Procedure, Faculty of Economy and Law

Sibay Institute (branch) of Bashkir State University,

21 Belova St., Sibay, Russia

ildar_bgu@mail.ru

Inna A. Sitnova

Dr. Sci. (Econ.), Prof.,

Sibay Institute (branch) of Bashkir State University,

21 Belova St., Sibay, Russia

Senior Researcher,

Sibay Branch of Institute for Strategic Studies of the Republic of Bashkortostan

1 Kutuzova St., Sibay, Russia

sinn01@mail.ru

Abstract. The article deals with the problems of working youth in the Republic of Bashkortostan, such as the low level of wages and housing, the lack of a unified approach to the age gradation of working youth, the inconsistency of information on the measures aimed at regulation of living conditions. We have reviewed the measures to support youth in the Russian Federation, as well as support programmes in the regions. It is concluded that, despite the work carried out and the state programs being implemented to ensure the living standards of young people, there are no measures that regulate the quality of living of working youth under the age of 35 , so a need to place them in a separate protected category of population arises.

Keywords: quality of living; working youth; support programmes; labour resources; population.

Статья поступила в редакцию 15.10.2020; одобрена после рецензирования 30.10.2020; принята к публикации 30.10.2020. 